\title{
The evolution of humor from male aggression
}

This article was published in the following Dove Press journal:

Psychology Research and Behavior Management

13 February 2012

Number of times this article has been viewed

\section{Sam Shuster \\ Newcastle University, Newcastle Upon Type, NEI 7RU, UK}

Correspondence: Sam Shuster Newcastle University, Newcastle Upon Tyne, NEI 7RU, UK

Email sam@shuster.eclipse.co.uk

\begin{abstract}
The response to seeing a man riding a unicycle was reported to be consistently related to the viewer's sex and stage of physical development. To see if this observation was universal, observations of responses were collected from 23 male and 9 female unicyclists aged 15-69 years, with 2-40 years cycling experience across four continents. With two exceptions among men, the findings were the same as those originally reported: children showed interest and curiosity, young girls showed little interest, while adult women showed a kindly, concerned, praising response. By contrast, boys showed physical aggression, which became more verbal, merging in the later teens to the snide, aggressive, stereotyped humorous response shown by adult males, which became less frequent in elderly men. The universality of the response across different individuals, environments, and dates of observation suggests an endogenous mechanism, and the association with masculine development relates this to androgen. The theoretical consequences are discussed. It is concluded that humor develops from aggression in males and is evolutionarily related to sexual selection.
\end{abstract}

Keywords: humor evolution, male aggressive behavior

\section{Introduction}

It was reported that, despite the great range of personal and individual differences in a population, the unpremeditated verbal responses to the sighting of a unicyclist by random passersby were consistent, repetitive, and stereotyped. ${ }^{1}$ Ninety percent of responses from women were supportive, praising, and concerned, whereas $80 \%$ of men responded with a snide, aggressive, repetitive joke, most often a variant of "lost a wheel"? In children, the response was one of interest and curiosity. In older boys, it was one of aggression, often physical. In the later teens this became more verbal, with transition to an aggressive, snide, adult male "joke". It was concluded that humor developed from male aggression. However, despite the large number of underlying observations, they were made by just one elderly male unicyclist in one small geographical area over a decade and a half ago. Thus, they can only be generalized if confirmed by unicyclists of different age, sex, region, country, and time. The aim of the present study was to gather evidence from the observations made by other unicyclists in other circumstances, then to consider the implications for the origins and purpose of humor.

\section{Materials and methods}

It was not possible to do a formal study of onlooker response to unicycling using different unicyclists in different parts of the world, or to secure a representative 
worldwide questionnaire. However, the increasing popularity of unicycling, and online access to its practitioners, allowed collection of observations of responses already noted in postings on unicyclist forums by unicyclists whose email addresses were online. In addition, observations were collected from five other unicyclists (four male and one female; from the UK, USA, Australia, and Asia) who had been given an outline of the originally reported findings and asked whether they had observed the same or different responses, and to describe the differences. Thus, an online search allowed the collection of unselected observations, already noted by unicyclists, of the spontaneous responses that had been made to them by onlookers.

\section{Results}

Onlooker responses observed by 23 male and 9 female unicyclists were obtained. The unicyclists were aged 15-69 years and had unicycled for between 2-40 years. Eight were from the UK, eight from the USA, and the remainder from Australia, Canada, Holland, Finland, Germany, Norway, New Zealand, and South Korea. One had unicycled in Canada, USA, and New Zealand. One had unicycled in USA and South Korea.

All but two men had recorded responses that were the same as those reported in the original publication. One of the two exceptions had observed the same responses initially but subsequently observed no response; the other had never observed negative responses. All of the 30 other unicyclists (21 male and 9 female) noted that adult male onlookers responded with the same repetitious, snide remarks made aggressively as a "joke", of which most were based on the single wheel, eg, "Do you know ...", "Have you noticed ...", "You have only ...", "Have you lost a wheel?" By contrast, women did not make aggressively humorous remarks; their responses were warm, appreciative, and supportive, with a concern for safety.

The male "joke" response, with its repetitive content and irritating, offensive intent, was observed by male and female unicyclists in many parts of the world:

"Most get the old 'where's your other wheel?' joke ... every time they go anywhere ... very annoying, they ignore it and don't respond anymore - or offer for the rude person to try their bike!" (Tasmania, Australia)

"Men always tries to be funny (everyone says the same), and women say a lot of nice things about how good I am and wonder how I make it.” (Norway)

The proportion of onlookers who responded was not recorded, but individual comments were suggestive of regional variations. A male unicyclist from New York City noted that fewer people responded there than in other cities in the USA, although the responses were identical. Another male observed that responses in a small village in the UK were fewer than in a large town. However, a greater number of unicyclists than those included in the present study would be required for sub-group analysis of possible environmental and other influences.

Unicyclists observed that young children showed interest and curiosity, which they communicated to their parents, and noted a subsequent transition of this response toward physical and verbal aggression in older boys - but not girls - with stone throwing, spitting, obstruction, and sudden shouts of "Fall off!" From puberty onwards, a change to an aggressively humorous response was observed in males but not in females. The particularly aggressive verbal behavior of young men in cars was also noted. All five unicyclists given access to an outline of the original findings responded by confirming that their own observations had been the same as those originally reported.

Suggested ripostes to the abrasive repetitious "jokes" made by male onlookers were posted to online sites, intended for use by fellow unicyclists. The postings showed that both male and female unicyclists experienced the same remarks, most often about the single wheel. "This is the thousandth time I've heard that today," is an example riposte.

\section{Discussion}

The intention of the present study was to see if the observations reported in a pilot study by a single, elderly male unicyclist in one UK town are confirmed by unicyclists of different ages, sexes, and locations, using data gathered from internet postings and from email correspondence. Although this method of data collection does not eliminate risks of self-selection and bias, the equal opportunity available to unicyclists to record conflicting observations makes it likely that these findings are representative; the consistency of the data gathered from the different sources gives further confidence. The data confirmed the originally reported observations, ${ }^{1}$ notably that children showed curiosity and adult women praised, whereas boys showed physical aggression that became verbal at puberty and merged into an aggressive, stereotyped "joke" response in adult males, which lessened in elderly men. The responses were universal, regardless of time, place, and unicyclist, even with regard to their gender.

The original study ${ }^{1}$ assumed that an unconscious response was being elicited by exposure to a novel, unexpected 
stimulus, which minimized conscious modification. Therefore, the stimulus was kept constant by cycling neutrally and wearing nondescript clothing. But, as the online accounts and photographs have no such constraints, the eliciting stimulus is taken to be the act of unicycling itself. The supposed importance of unexpectedness was supported by accounts from unicyclists who experienced aggressive (male) jokes when unicycling recreationally, but applause when performing unicycling as entertainment. Similarly, a professional juggler and unicyclist noted the same difference in responses to juggling. Three men noted loss of the original male "joke" response on repeated viewing.

The repetitive nature of the male "joke" response, in particular the frequent reference to number of wheels, was repeatedly confirmed. This consistency has parallels with other circumstances. A sartorially-exposed waitress noted:

"Most men comment on the 'lovely jugs' when I carry

pitchers to their tables. ... I just wish they would come up

with something original."

The importance of repetition is well known by professional comedians, who develop and repeat a simple catchphrase to elicit an amused response, despite it having little intrinsic humor.

The gross change in the responses of males and females at different stages of development can reasonably be taken as age-sequential because it has been observed by many individuals in various geographic regions over a 40 -year period. This consistent evolution of onlooker response from childhood to old age, regardless of social, individual, and time and place differences, puts beyond credibility the repetitive concurrence of environmental factors singular enough to cause the observed sameness of response. Thus, the response can only be part of a common biological mechanism. Its clear relationship to masculine development is strong evidence that the mechanism is sexual. The association of the male response with the time of virility suggests less a genetic effect than a direct effect of androgen, a hormone associated with aggressive behavior in men and other male animals, whether by modulation ${ }^{2}$ or gene expression. ${ }^{3,4}$ Nevertheless, it is important to know whether there is a prepubertal sex difference, related to aggression, in the production, exhibition, and appreciation of humor.

Can the spontaneous response to seeing a unicyclist, which suggests that adult male humor arises with transition toward aggression, be extended to humor in general? Such an extension could explain the association of humor with torture methods, which often show a perverse comedy in their conception, if not in their execution, and with the smiling faces of onlookers often apparent in pictorial records. Similarly, the laughter associated with tickle, considered by some to be the origin of humor, ${ }^{5-8}$ like itch, is neurologically related to pain and moves easily into agony. A relationship between humor and aggression may also help explain the enjoyment of practical jokes, "gallows humor", 9 and the humor of verbal combat, whether over the dinner table or on the football terrace, where its enjoyment can relate to the discomfort it causes. The association of humor with aggression is well accepted in the arts:

"Perhaps in nearly every joy, as certainly in every pleasure,

cruelty has its place." (Oscar Wilde, The Picture of Dorian

Gray)

Many aspects of that relationship have been considered on theoretical or experimental grounds. ${ }^{5,9-14}$ The observed humor responses to unicycling were crude, simple, and repetitive. Could further evolution in humor occur with loss of its aggressive root? Such a change could be expected as an inevitable consequence of biological fidgeting. But, despite some psychological and historical suggestions, ${ }^{7-11,15}$ there are no studies of the development of other humor responses in other situations that explore this possibility.

Because the sexual divide in the observed humorous responses is so great and consistent, it has to be assumed to have (or have had) a "purpose". It is reasonable to think of that purpose in evolutionary terms. Since it is unlikely that the capacity to make jokes directly enhances survival, (as many a funny individual might otherwise have testified), one possibility is that its advantage lies in mate selection, ${ }^{16,17}$-a well debated idea. ${ }^{14,18-22}$ However, the evidence for this possibility is inconclusive, despite many accounts of sexual differences in humor production, appreciation, and attractiveness. ${ }^{6,14,23-31}$ The present findings suggest that what is to be revealed by further studies of the attractiveness of male humor to females, and the determination of any selective advantage, may well be limited by the type of humor under study (eg, the repetitive-aggressive humor observed by unicyclists). The findings further suggest that such studies could be improved by the use of objective, stimulus-response methods. For example, measurement of changes in brain blood flow, muscle tone, pupil size, pain threshold, and stress sweating allow the quantification of subjective attributes, ${ }^{2}$ and avoid the vagaries of questionnaires, ${ }^{31-33}$ which are inevitably limited by preconceived questions and the risk of consciously modified answers.

The initial or past function of an attribute is not proof of its continued function. New studies are needed to show whether, despite its origins, humor is simply an antler 
decorating the wall of our sexual past; an evolutionary epiphenomenon now playfully used for other purposes. But, if the observed development of humor in man is assumed to imply an evolutionary advantage, or is a marker of one, there are obvious reciprocal implications for humor in females, because it follows that females must have the capacity to recognize and "grade" the humor on offer (presumably for mate selection). Since the ability to recognize the best on offer implies selection from a field that includes the "less than best", it is further implied that the ability of women to appreciate humor can only lie between "as good as" and "better than" that of men, albeit that men seem better at humor production. There have been many studies of malefemale differences in humor, but none have addressed these possibilities.

The findings imply that, whereas production and exhibition of humor develop from aggression in males, only appreciation needs to develop concomitantly in females. It is a commonplace observation that production, exhibition, and appreciation of humor are distinct: the seriousness of the comic's demeanor in presenting his script writer's joke often has an inverse relationship to the appreciative response it produces. Their dissociation is further evidenced by the equally commonplace observation that, whilst most comedians are men, many in the appreciative audience are women. In these respects, the experimental possibilities arising from the present findings are considerable. They include the testing of differences between production, exhibition, and appreciation of different types of humor in relationship to the stage and state of sexual development; the effect of certain endocrine disorders and hormone treatments; a closer definition of the aggressive root of humor, the persistence of aggression as a component of humor, and whether it makes male humor more acceptable to females; or is trumped by subtlety and loss of repetition; and the relationships between humor production, exhibition, and appreciation and the social, physical, and sexual success of individual men and women.

In conclusion, the present study has confirmed the originally reported findings and extended them. The consistent response to seeing a unicyclist is related to sexual development, suggesting that humor develops from aggression in males. The present study also suggests a new approach to the experimental questions raised, including whether such a narrow study can reliably produce such wide-ranging answers.

\section{Disclosure}

The author reports no conflict of interest in this work.

\section{References}

1. Shuster S. Sex, aggression, and humour: responses to unicycling. BMJ. 2007;335:1320-1323.

2. Shuster S. Reason and the rash. Proc Roy Inst Great Brit. 1981;45: 136-163.

3. Rees J, Shuster S. Pubertal induction of sweat gland activity. Clin Sci. 1981;60:689-692.

4. Thody A, Shuster S. Control and function of sebaceous glands. Physiol Rev. 1989;69:383-416.

5. Gervais M. The evolution and function of laughter and humor: a synthetic approach. Quart Rev Biol. 2004;80:395-430.

6. Provine RR. Laughter: A Scientific Investigation. London: Faber and Faber; 2000.

7. Coser RL. Some social functions of laughter: a study of humor in a hospital setting. Hum Relat. 1959;12:171-182.

8. Coser RL. Laughter among colleagues: a study of the social functions of humor among the staff of a mental hospital. Psychiat. 1960;23: $81-95$.

9. Kuhlman TL. Gallows humor for a scaffold setting: managing aggressive patients on a maximum-security forensic unit. Hosp Community Psychiatry. 1988;39:1085-1090.

10. Prerost FJ, Brewer RE. Common elements of sex and aggression as reflected in humor preferences. Pers Soc Psychol Bull. 1974;1: 189-191.

11. Love AM, Deckers LH. The indication of sexual and aggressive similarities through humor appreciation. J Psychol. 1975;91:283-288.

12. Ruch W. The Sense of Humor: Exploration of a Personality Characteristic. New York: Mouton de Gruyter; 1998.

13. Veatch TC. A theory of humor. Humor. 1999;11:161-215.

14. Weisfeld GE. Humor appreciation as an adaptive esthetic emotion. Humor. 2006;19:1-26.

15. Shapiro JP, Baumeister RF, Kessler JW. A three-component model of children's teasing: aggression, humor, and ambiguity. J Soc Clin Psychol. 1991;10(4):459-472.

16. Miller GF. Sexual selection for indicators of intelligence. Novartis Found Symp. 2000;233:260-270.

17. Miller GF. The Mating Mind. London: Heinemann; 2000.

18. Roney JR. Likeable but unlikely, a review of The Mating Mind by Geoffrey Miller. Pyscoloquy. 2002;13(10):1-5.

19. Storey T. Humor and sexual selection. Human Nature. 2003;14: 319-336.

20. Bressler E, Martin RA, Balshine S. Production and appreciation of humor as sexually selected traits. Evol Hum Behav. 2005;27:121-130.

21. Bressler ER, Balshine S. Influence of humor on desirability. Evol Hum Behav. 2006;27:29-39.

22. Tisljar R, Bereczkei T. An evolutionary interpretation of humor and laughter. J Cult Evol Psychol. 2005;3:301-309.

23. Brodzinsky DM, Barnet K, Aiello JR. Sex of subject and gender identity as factors in humor appreciation. Sex Roles. 1981;7:561-573.

24. Daniel H. Values in mate selection: a 1984 campus survey. Coll Stud J. 1985;19:44-50.

25. Buss DM, Schmitt DP. Sexual strategies theory: an evolutionary perspective on human mating. Psychol Rev. 1993;100:204-232.

26. Lundy DE, Tan J, Cunningham MR. Heterosexual romantic preferences: the importance of humor and physical attractiveness for different types of relationships. Pers Relatsh. 1998;5:311-325.

27. Campbell O, Martin RA, Ward JR. An observational study of humor use while resolving conflict in dating couples. Pers Relatsh. 2008; 15:41-55.

28. Hay J. Functions of humor in the conversations of men and women. J Pragmat. 1974;32:709-742.

29. Attardo S. Introduction: the pragmatics of humor. J Pragmat. 2003;35:1282-1294.

30. Kotthoff H. Gender and humor: the state of the art. J Pragmat. 2006;38:4-25. 
31. Buss DM. The Evolution of Desire: Strategies of Human Mating. New York: Basic Books; 2003.

32. Buss DM. Sex differences in human mate preferences: evolutionary hypotheses tested in 37 cultures. Behav Brain Sci. 2000;12:1-49.
33. Holmes J. Sharing a laugh: pragmatic aspects of humor and gender in the workplace. J Pragmat. 2006;38:26-50.

Psychology Research and Behavior Management

\section{Publish your work in this journal}

Psychology Research and Behavior Management is an international, peerreviewed, open access journal focusing on the science of psychology and its application in behavior management to develop improved outcomes in the clinical, educational, sports and business arenas. Specific topics covered include: Neuroscience, memory \& decision making; Behavior modification \& management; Clinical applications; Business \& sports performance management; Social and developmental studies; Animal studies. The manuscript management system is completely online and includes a quick and fair peer-review system. Visit http://www.dovepress. com/testimonials.php to read real quotes from published authors.

Submit your manuscript here: http://www.dovepress.com/psychology-research-and-behavior-management-journal 